\title{
Cisplatin plus oral etoposide (EoP) combination is more effective than paclitaxel in patients with advanced breast cancer pretreated with anthracyclines: a randomised phase III trial of Turkish Oncology Group
}

\author{
F Icli*,', H Akbulut', A Uner², B Yalcin', E Baltali ${ }^{3}$, M Altinbas ${ }^{4}$, Ș Coşkun ${ }^{4}$, S Komurcu ${ }^{5}$, M Erkisi', \\ A Demirkazik', FC Senler', O Sencan', A Büyükcelik', C Boruban', H Onur', N Zengin' and SD Sak \\ 'Department of Medical Oncology, Ibni Sina Hospital, Ankara University School of Medicine, Ankara 06 I00, Turkey; ${ }^{2}$ Department of Medical Oncology, \\ Gazi University Faculty of Medicine, Ankara, Turkey; ${ }^{3}$ Department of Medical Oncology, Hacettepe University Faculty of Medicine, Ankara, Turkey; \\ ${ }^{4}$ Department of Medical Oncology, Erciyes University Faculty of Medicine, Kayseri, Turkey; ${ }^{5}$ Department of Medical Oncology, GATA, Ankara, Turkey; \\ ${ }^{6}$ Department of Medical Oncology, Cukurova University Faculty of Medicine, Adana, Turkey; ${ }^{7}$ Department of Pathology, Ankara University School of \\ Medicine, Ankara, Turkey
}

\begin{abstract}
Our objective was to determine whether oral etoposide and cisplatin combination (EoP) is superior to paclitaxel in the treatment of advanced breast cancer (ABC) patients pretreated with anthracyclines. From December 1997 to August 2003, 20I patients were randomised, 100 to EoP and 101 to paclitaxel arms. Four patients in each arm were ineligible. The doses of etoposide and cisplatin were $50 \mathrm{mg}$ p.o. twice a day for 7 days and $70 \mathrm{mg} \mathrm{m}^{-2}$ intravenously (i.v.) on day I, respectively, and it was $175 \mathrm{mg} \mathrm{m}^{-2}$ on day I for paclitaxel. Both treatments were repeated every 3 weeks. A median of four cycles of study treatment was given in both arms. The response rate obtained in the EoP arm was significantly higher (36.3 vs 22.2\%; $P=0.038$ ). Median response duration was longer for the EoP arm (7 vs 4 months) ( $P=0.132$ ). Also, time to progression was significantly in favour of the EoP arm (5.5 vs 3.9 months; $P=0.003)$. Median overall survival was again significantly longer in the EoP arm ( 14 vs 9.5 months; $P=0.039)$. Toxicity profile of both groups was similar. Two patients in each arm were lost due to febrile neutropenia. The observed activity and acceptable toxicity of EoP endorses the employment of this combination in the treatment of $A B C$ following anthracyclines.

British Journal of Cancer (2005) 92, 639-644. doi:I0.1038/sj.bjc.6602388 www.bjcancer.com
\end{abstract}

(c) 2005 Cancer Research UK

Keywords: advanced breast cancer; cisplatin; etoposide; paclitaxel; anthracycline

Survival in breast cancer is improving, mostly related to early diagnosis. However, at least $40 \%$ of the early cases present with recurrent disease following curative surgery \pm adjuvant systemic therapy. Although hormonal treatment is preferred for advanced breast cancer $(\mathrm{ABC})$, chemotherapy $(\mathrm{CT})$ is required for hormone receptor-negative and hormone refractory disease.

Anthracycline combinations have been commonly used to treat for $\mathrm{ABC}$ for a long time. Recently, taxanes became the standard treatment for these patients following anthracycline failure. In randomised trials, docetaxel (Taxotere ${ }^{\mathbb{R}}$ ) was found comparable to 5 -fluorouracil + vinorelbine (FUN) and more active than mitomycin $\mathrm{C}+$ vinblastine (MV), and methotrexate + 5-fluororacil (MF) in this group of patients (Nabholtz et al, 1999; Sjöström et al, 1999; Bonneterre et al, 2002). However, there are limited numbers of randomised trials comparing the efficacy of paclitaxel to other

*Correspondence: Professor Dr F Icli; E-mail: ficl@@dialup.ankara.edu.tr This work was presented at the 27th ESMO Congress. Bristol Myers Squibb (Turkey) supplied limited number of paclitaxel for this trial Received 15 June 2004; revised 8 November 2004; accepted 16 December 2004 drugs or combination CTs in anthracycline-pretreated patients. In a small phase II randomised trial, capecitabine was found to be as effective as paclitaxel in patients with $\mathrm{ABC}$ pretreated with anthracyclines (Talbot et al, 2002). Recently, given as a single agent, docetaxel was reported to be more active than paclitaxel in terms of overall response rates, time to progression (TTP) and survival in patients with $\mathrm{ABC}$ pretreated with anthracyclines (Ravdin et al, 2003).

Another active but less popular treatment in anthracyclinepretreated patients with $\mathrm{ABC}$ is etoposide + cisplatin (EoP). A higher response rate than that achieved with CMF was observed by giving EP as first-line treatment in a small randomised trial (Cocconi et al, 1991). Etoposide + cisplatin was also found as an active treatment for $\mathrm{ABC}$ following anthracyclines in the several phase II trials (Cox et al, 1989; Krook et al, 1990; Icli et al, 1992; Remick et al, 1996). Furthermore, 42 and 50\% response rates with acceptable side effects were reported by prolonged administration of oral EoP in two phase II trials, which were higher than those obtained by giving paclitaxel in $\mathrm{ABC}$ patients pretreated with anthracyclines (Icli and Demirkazik, 1998; Fried et al, 2000). Cost of the drugs in EoP is much lower than taxanes. 
With the premise that EoP may be more effective than paclitaxel, Turkish Oncology Group (TOG) decided to compare the efficacy of EoP with paclitaxel in anthracyline-pretreated patients with $A B C$ in a phase III randomised trial.

\section{PATIENTS AND METHODS}

\section{Patients}

After obtaining written informed consent, patients with histologically or cytologically confirmed locally advanced or metastatic breast cancer were randomised if they meet the following criteria: measurable or evaluable disease (metastases to skin, pleura and peritoneum), age 18-70 years, performance status 2 or less according to WHO criteria, pretreatment with anthracyclines, negative hormone receptors or hormone refractory disease, adequate bone marrow reserve measured as neutrophil count $\geqslant 2 \times 10^{9} 1^{-1}$ and platelet count $\geqslant 100 \times 10^{9} 1^{-1}$, normal BUN, serum creatinine and bilirubin levels and AST and ALT levels $<4$ times upper normal limits.

Criteria for exclusion were presence of second primary malignancy or brain metastasis as the only metastatic site. Brain metastasis well controlled with radiotherapy, in addition to other sites of metastasis was not an exclusion criterion.

Patients with disease progression while receiving anthracyclinebased $\mathrm{CT}$ for $\mathrm{ABC}$, relapse within 6 months following adjuvant anthracycline-based CT and no response after two or more cycles of anthracycline-based $\mathrm{CT}$ for $\mathrm{ABC}$, or responded to anthracyclines for $\mathrm{ABC}$ or received adjuvant anthracyclines and relapsed after 6 months (total dosage $\geqslant 360 \mathrm{mg}$ of doxorubicin or $\geqslant 450 \mathrm{mg}$ of epirubicin) were regarded as anthracycline pretreated.

\section{Study design}

This was a prospective randomised nonblinded multicentre phase III study. No stratification was carried out for prognostic factors or centers. Patients were centrally randomised to either paclitaxel or EoP arms. The primary end point was TTP. Secondary end points were tumor response rate, duration of response and overall survival (OS).

\section{Treatment}

Chemotherapy doses and schedules were as follows. Paclitaxel $175 \mathrm{mg} \mathrm{m}^{-2}$ intravenously (i.v.) on day 1 or etoposide $50 \mathrm{mg}$ b.i.d p.o. daily for 7 days + cisplatin $70 \mathrm{mg} \mathrm{m}^{-2}$ i.v. on day 1 with adequate i.v. hydration every 3 weeks. At least two cycles of study treatment was planned for each patient, unless there was clear evidence of progression following the first cycle. Crossover was allowed for patients with progressive disease at any time. Also, patients with stable disease after at least two cycles of study treatment could be crossed over at the discretion of the investigator. Crossover was not mandatory.

Paclitaxel dose was reduced to $135 \mathrm{mg} \mathrm{m}^{-2}$ in case of previous $\mathrm{RT}$ to pelvis and vertebrae or if ALT and/or AST were more than three times upper normal limits. If grade 3-4 hematological toxicity was observed in the prior cycle of the treatment, paclitaxel was reduced to $135 \mathrm{mg} \mathrm{m}^{-2}$ (or $110 \mathrm{mg} \mathrm{m}^{-2}$ if prior dose was $135 \mathrm{mg} \mathrm{m}^{-2}$ ). Likewise, etoposide was reduced to $50 \mathrm{mg}$ p.o. twice a day for 5 days and cisplatin to $50 \mathrm{mg} \mathrm{m}^{-2}$. Treatment was delayed if there was grade 2 or more toxicity at the scheduled date of study treatment.

\section{Assessment and follow-up}

Physical examination, complete blood count, liver and renal function tests, serum CA-15-3, chest X-ray, abdominal ultrasonography (USG) or computerised tomoraphy were carried out before the first cycle of study treatment. Thorax computerised tomography (CT) was carried out only if lung metastasis was suspected from the chest X-ray. Physical examination and routine blood tests were repeated before each cycle of CT. Chest X-ray or thorax CT was required every 6 weeks during the treatment and every 3 months post-treatment. Likewise, abdominal USG/CT was required every 6 weeks during the treatment and every 3 months posttreatment if intra-abdominal metastasis was present. Response to treatment was evaluated every 6 weeks, unless there was evidence of progressive disease on physical examination in 3 weeks. The same assessment method used to determine the disease status at baseline was used consistently for efficacy evaluation throughout the study and follow-up. Routine post-treatment follow-up was every 1-3 months at the discretion of the investigator in case of lack of any symptoms or signs suggesting progressive disease.

Response to study treatment was assessed according to WHO criteria. Response rates were evaluated for the actual treatments patients had received. Responses were reviewed by two independent experts to confirm the response status blindly for treatment received. Response duration was measured from the date of response to date of progression. Time to progression was the duration between the first day of study treatment and date of progression. Likewise OS was accepted as the time interval between the first day of study treatment and date of death. Overall survival was calculated on intent-to-treat basis.

\section{Statistical considerations}

A total of 146 events were planned based on the log-rank test, for a median TTP ratio of 1.65 , for two-sided 0.05 type 1 error rates and 0.80 power. Comparisons between the response rates, patient characteristics and adverse events were carried out by using $\chi^{2}$ test. Time to progression and OS parameters were analysed using the Kaplan-Meier method and log-rank test. Stepwise Cox's regression analysis was used to assess the significant predictors for survival. Time interval from diagnosis and relapse to study treatment, CT, relative dose intensity (RDI), number of metastatic sites and age were used as continuous variables and type of study treatment as a dichotomous variable.

\section{RESULTS}

\section{Patient characteristics}

Between December 1997 and August 2002, 201 patients from seven Oncology centres in Turkey were enrolled. A total of 100 patients were randomised to EoP arm and 101 to paclitaxel arm. Randomisation was carried out centrally by the data centre of TOG. Four patients in each arm were ineligible because one patient in each arm had poor performance status and were lost before the start of study treatment, three patients in the EoP and two in the paclitaxel arms withdrew their consents and one patient in the paclitaxel arm was injured in a car accident and the treatment could never be started. Thus, there were 96 eligible patients in the EoP arm and 97 in the paclitaxel arm. Patient characteristics including prior treatments are depicted in Table 1 . There were no substantial differences between the two arms. There were two evaluable patients, one in paclitaxel and one in EoP arms, who had cytologically proven metastatic disease of pleura with effusion. All other patients had measurable disease. The median number of treatment cycles were 4 (ranges 1-8) for both arms. In total, 68 patients in the EoP and 75 patients in the paclitaxel arm received three to six cycles of treatment. Only four and seven patients in the EoP and paclitaxel arms, respectively, were given one cycle of treatment. Relative dose intensities were 85.17 and $85.74 \%$ for the etoposide and cisplatin, respectively, vs $89.27 \%$ for the paclitaxel. While paclitaxel dosage was reduced in five patients (5\%), EP was 
Table I Patient characteristics

\begin{tabular}{|c|c|c|c|}
\hline & $\operatorname{EoP}(n=96)$ & Paclitaxel $(n=97)$ & $P$-value \\
\hline Median age (years) (range) & $47(26-69)$ & $49(24-70)$ & 0.377 \\
\hline \multicolumn{4}{|l|}{ Performance status (WHO) } \\
\hline 0 & 20 & 17 & \\
\hline I & 50 & 45 & 0.401 \\
\hline 2 & 26 & 35 & \\
\hline \multicolumn{4}{|l|}{ Site of metastasis } \\
\hline Locally advanced & 4 & 3 & \\
\hline Skin & 47 & 37 & 0.148 \\
\hline Lymph node & 22 & 15 & \\
\hline Lung & 47 & 47 & \\
\hline Liver & 35 & 46 & 0.145 \\
\hline Bone & 45 & 39 & 0.385 \\
\hline Brain & 3 & 3 & \\
\hline Peritoneum & 5 & 2 & \\
\hline \multicolumn{4}{|l|}{ Number of metastatic sites } \\
\hline 1 & 29 & 29 & \\
\hline 2 & 33 & 44 & 0.354 \\
\hline 3 or more & 34 & 24 & \\
\hline \multicolumn{4}{|l|}{ Hormone receptor } \\
\hline ER/PR+ & 29 & 31 & \\
\hline ER/PR- & 15 & 22 & 0.298 \\
\hline Unknown & 52 & 44 & \\
\hline \multicolumn{4}{|l|}{ Oncogene expression } \\
\hline HER2+ & 11 & 11 & \\
\hline HER2- & 9 & 13 & 0.763 \\
\hline Unknown & 76 & 73 & \\
\hline TIDTR & $28.4 \pm 5.0$ & $28.9 \pm 3.9$ & 0.350 \\
\hline \multicolumn{4}{|l|}{ Prior treatments } \\
\hline Surgery & 72 & 72 & 1.000 \\
\hline Radiotherapy & & & 0.285 \\
\hline Adjuvant & 17 & 17 & \\
\hline Metastatic & 18 & 11 & \\
\hline Hormone & & & 0.158 \\
\hline Adjuvant & 10 & 18 & \\
\hline Metastatic & 14 & 16 & \\
\hline Prior anthracyclines ${ }^{\mathrm{a}}$ & & & 0.663 \\
\hline | & 33 & 32 & \\
\hline 2 & 2 & 4 & \\
\hline 3 & 18 & 13 & \\
\hline 4 & 43 & 48 & \\
\hline Setting of study drugs & & & 0.947 \\
\hline First line & 18 & 20 & \\
\hline Second line & 59 & 58 & \\
\hline Third line & 19 & 19 & \\
\hline
\end{tabular}

EoP: cisplation+oral etoposide; $\mathrm{WHO}=$ World Health Organization; TIDTR: time from initial diagnosis to treatment. ${ }^{\mathrm{a}}$ : disease progression while receiving anthracycline-based $C T$ for $A B C$; 2: relapse within 6 months following adjuvant anthracycline-based $C T$; 3: no response after two or more cycles of anthracyclinebased $C T$ for $A B C$; 4: responded to anthracyclines for $A B C$ or received adjuvant anthracyclines and relapsed after 6 months (total dosage $\geqslant 360 \mathrm{mg}$ of doxorubicin or $\geqslant 450 \mathrm{mg}$ of epirubicin). $E R=$ oestrogen receptor, $P R=$ progesterone receptor; HER2 $=c-$ ErbB-2

reduced in 10 patients (10\%) because of previous radiation to pelvis.

\section{Efficacy}

A total of 91 patients in the EoP arm and 95 in the paclitaxel arm were evaluable for response. One patient was given paclitaxel instead of assigned EoP and was excluded from response evaluation. However, her survival duration was included in the
Table 2 Results of the response evaluation and time-related variables

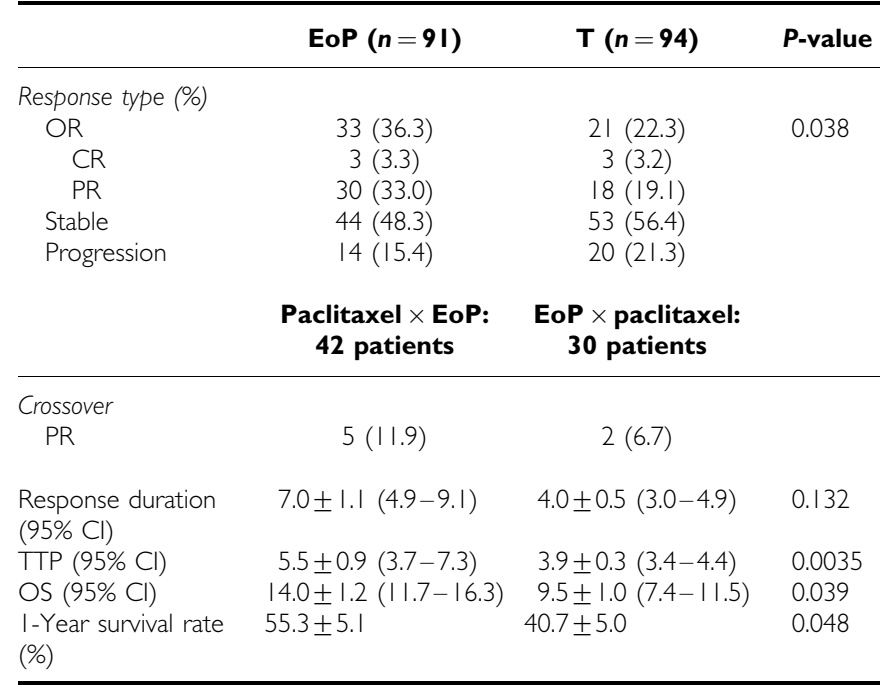

EoP = etoposideplus cisplatin; $T \mathrm{TP}=$ time to progression; $\mathrm{Cl}=$ confidence interval. $\mathrm{OR}=$ overall response; $\mathrm{CR}=$ complete response; $\mathrm{PR}=$ partial response.

EoP arm on intent-to-treat basis. Two patients in the EoP arm and three in the paclitaxel arm died before any response evaluation. Likewise, two patients in the EoP arm did not come for further treatment following the first cycle. Response to study treatment is shown in Table 2. Total response rates were 36.3 and $22.2 \%$ in the EoP and paclitaxel arms, respectively $(P=0.038)$. Complete response was achieved in three patients in each arm.

Five out of 42 patients $(11.9 \%)$ crossed over to EoP from paclitaxel vs two out of 30 patients $(6.7 \%)$ crossed over to paclitaxel achieved a PR. Until July 2003, disease progression was observed in 182 patients and 165 had died.

The duration of response was not significantly different between the two arms (Table 2). Median response duration for patients in the EoP and paclitaxel arms was 7 and 4 months, respectively $(P$ : 0.132 ). Time to progression was significantly in favour of the EoP arm ( $P: 0.003)$. Median TTP was 5.5 months for the EoP arm and 3.9 months for the paclitaxel arm (Figure 1). Likewise, median survival for patients in the EoP arm (14 month) was longer than those in the paclitaxel arm (9.5 months) $(P=0.039)$ (Figure 2$)$. The 1 -year survival rate was also in favour of the EoP arm, although the difference was not statistically significant (55.3 vs $40.7 \%$; $P=0.168)$.

Although not significant, overall response rates were in favour of EoP arm in patients who had adjuvant anthracyclines more than 6 months ago and those who were resistant to prior anthracyclines for metastatic disease or relapsed within 6 months of adjuvant anthracyclines when compared to paclitaxel arm (36.8 vs $33.3 \%$ and $23.3 v s 18.8 \%$, respectively). In patients who responded to prior anthracycline treatment, EoP has yielded a significantly higher response rate ( $55.6 v s 17.9 \% ; P=0.005)$. While there was no significant difference in terms of TTP in patients with adjuvant anthracyclines more than 6 months ago $(5.0 \pm 1.0$ vs $4.6 \pm 0.5$ months; $P=0.611)$, it was significantly higher in favour of EoP arm in anthracycline-responsive or -resistant patients $(4.5 \pm 1.1 \mathrm{vs}$ $3.0 \pm 1.1$ months, $P=0.005 ; \quad 6.0 \pm 1.0$ vs $3.5 \pm 0.3$ months, $P=0.006)$.

Multivariate analysis including time interval from diagnosis and relapse to study treatment, CT, RDI, number of metastatic sites, age and type of study treatment showed that only type of study treatment had significant impact on survival $(P=0.0281)$. The only other parameter that was found to have an impact on OS in multivariate analysis close to statistical significance was the number of metastatic sites $(P=0.059)$. 
642

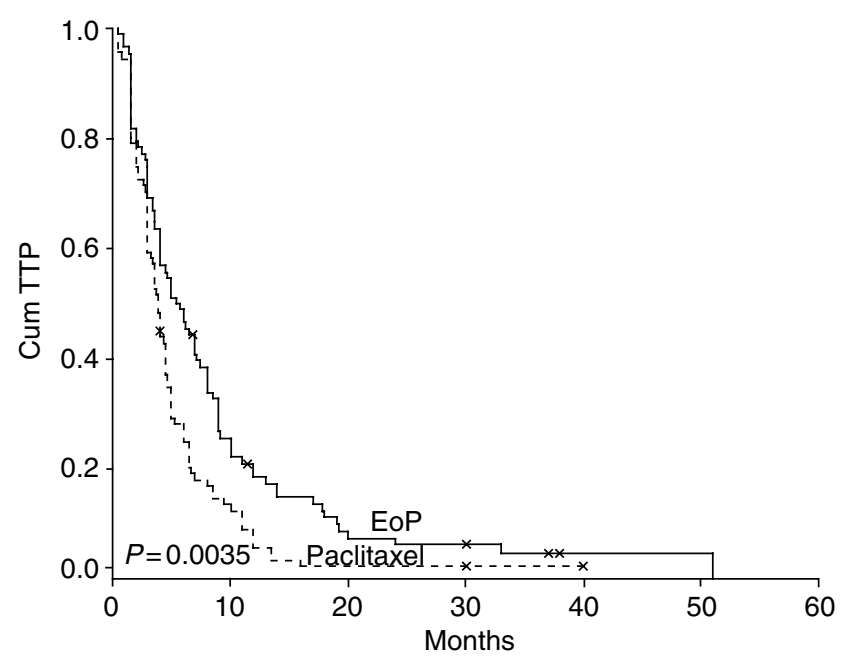

Figure I Kaplan-Meier curves for TTP according to the assigned arms.

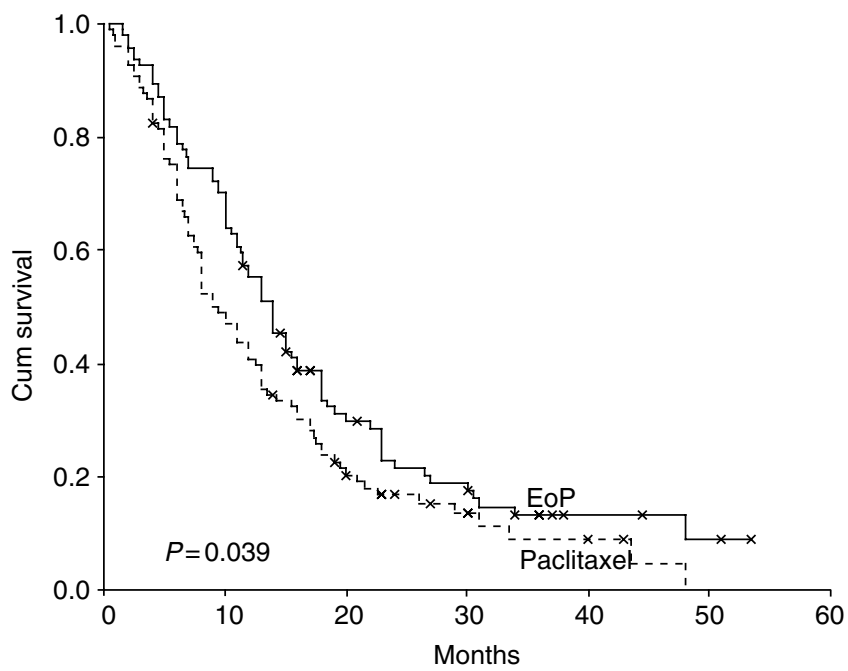

Figure 2 Kaplan-Meier curves for OS according to the assigned arms.

\section{Toxicity}

Chemotherapy toxicity is shown in Table 3. Complete blood counts were required every 3 weeks unless a febrile episode occurred. Therefore, the nadirs for neutrophils and platelets between the treatment cycles were not assessed adequately. Grade 4 haematologic toxicities were observed in four and six patients in the EP and paclitaxel arms, respectively. Delay of study treatment for at least 1 week due to myelosuppression occurred in 21 patients in the EoP group $v s$ in three patients in the paclitaxel group. Likewise, 23 and 17 patients had delayed treatments from other causes in the EoP and paclitaxel groups, respectively. Two patients in each arm were lost probably related to treatment toxicity. The causes of deaths were febrile neutropenia. Also, one patient was lost with fulminant hepatitis 4 weeks after the first dose of paclitaxel. Grade 3 nausea was more common in the EoP arm (15 patients). On the other hand, there were few patients with grade 3 arthralgia and neurologic toxicity in the paclitaxel arm. Likewise, three patients in the paclitaxel arm suffered from congestive heart failure while taking study treatment.
Table 3 Summary of common toxicities

\begin{tabular}{|c|c|c|c|c|}
\hline & \multicolumn{2}{|c|}{ EoP $(n=96)$} & \multicolumn{2}{|c|}{$\mathbf{T}(n=97)$} \\
\hline & Grade 3 & Grade 4 & Grade 3 & Grade 4 \\
\hline \multicolumn{5}{|l|}{ Haematological } \\
\hline Anaemia & 3 & 0 & 0 & 0 \\
\hline Neutropenia & 14 & $4^{\mathrm{a}}$ & 5 & $6^{b}$ \\
\hline Thrombocytopenia & । & 0 & 1 & I \\
\hline Nausea & 15 & 0 & I & 0 \\
\hline Arthralgia & 0 & 0 & 3 & 0 \\
\hline Neurologic & 0 & 0 & I & 0 \\
\hline Cardiac & $1^{c}$ & 0 & $3^{d}$ & 0 \\
\hline Toxic death & & 2 & & 3 \\
\hline
\end{tabular}

\section{DISCUSSION}

This is the first randomised trial comparing the efficacy of paclitaxel with other CT in anthracycline-pretreated patients with breast cancer. In this trial, EoP was found to have higher efficacy in terms of response rates, TTP and OS when compared to paclitaxel.

The additive and synergistic effects of cisplatin and etoposide in experimental models have been reported previously (Burchenal et al, 1979; Mabel and Little, 1981). Although EP has been commonly employed in lung cancer and germ cell tumors, it is not a well-established treatment for patients with breast cancer. Nevertheless, cisplatin was found to be an active drug in breast cancer in 1980s (Sledge and Roth, 1989). However, early trials with single agent i.v. etoposide in previously treated patients with $\mathrm{ABC}$ were not promising (Sledge, 1991).

The efficacy of EP was assessed in eight phase 2 trials including 260 patients previously treated for ABC (Athanassiades et al, 1986; Cocconi et al, 1986; Giaccone et al, 1988; Cox et al, 1989; Krook et al, 1990; Icli et al, 1992; Ceci et al, 1995; Remick et al, 1996). A total response rate of $26.8 \%$ was obtained by giving etoposide $100-$ $130 \mathrm{mg} \mathrm{m}^{-2}$ i.v. for 3-5 days and cisplatin $60-100 \mathrm{mg} \mathrm{m}^{-2}$ i.v. every 3 weeks to these heavily pretreated patients. The highest rate of grade 3-4 leukopenia was $31 \%$ in one trial, and altogether four toxic deaths were reported in these trials.

Following the emergence of oral etoposide, the role of prolonged oral etoposide in the treatment of breast cancer was investigated in five phase II trials (Calvert et al, 1993; Martin et al, 1994; Palombo et al, 1994; Atienza et al, 1995; Bontenbal et al, 1995). Unlike the results of single agent i.v. etoposide, the overall response rate was $23.8 \%$ in 143 patients with $A B C$, most of whom were pretreated. Etoposide was utilised 50-100 mg p.o. for 14-21 days every 3-4 weeks in these trials. Myelosuppression, more prominent with 21 days of etoposide, and alopecia were notable toxicities in these trials.

So far, only two phase II trials looked into the role of oral EoP in ABC (Icli and Demirkazik, 1998; Fried et al, 2000). In our phase II trial, we have used the same dosage and schedule of EoP as in the present study. Out of $35(42.8 \%)$ heavily pretreated patients, 15 responded. Median response duration and OS were 6 and 8 months, respectively. Grade 3 leukopenia was observed in $14.3 \%$ of the patients and only one patient had grade 4 anaemia.

A lower dosage of cisplatin $\left(50 \mathrm{mg} \mathrm{m}^{-2}\right)$ and longer duration of oral etoposide ( $50 \mathrm{mg} \mathrm{m}^{-2}$ for 17 days) were utilised in the second trial by Fried et al. In 26 patients previously exposed to anthracyclines, $50 \%$ response rate with 7 months of response duration has been reported (Fried et al, 2000). Four patients (15\%) required hospitalisation for neutropenic fever in that trial. The response rate achieved in the present randomised study (36.3\%) is 
close to that obtained in our previous phase 2 trial $(42.8 \%)$. Likewise, the $22.2 \%$ response rate obtained in the paclitaxel arm is comparable with those achieved in previous trials employing $175 \mathrm{mg} \mathrm{m}^{-2}$ i.v. paclitaxel every 3 weeks in anthracyclinepretreated patients (Abrams et al, 1995). Both results of the past phase 2 trials and present randomised trial are in favour of EoP when compared to paclitaxel. On the other hand, myelotoxicity of EoP was somewhat higher than that of paclitaxel (18vs $11 \%$ grade 3-4 toxicity). Likewise, more patients in the EoP arm had delayed treatment interval due to toxicity. One might argue that the efficacy of paclitaxel could be increased by employing higher and more myelotoxic dosages. However, a randomised trial failed to show any favourable effect of higher than $175 \mathrm{mg} \mathrm{m}^{-2}$ of paclitaxel every 3 weeks in $A B C$, which excludes such an explanation of the lower efficacy of paclitaxel when compared to EoP in our trial (Winer et al, 2004).

Also, it was gratifying to see that both TTP and OS were significantly higher in the EoP arm when compared to paclitaxel arm, which has not been usual for randomised CT trials involving patients with ABC. Both TTP and OS curves show a stable progress in favour of the EoP arm (Figures 1 and 2). Although there were some minor differences in terms of patient characteristics between the two groups, they had no significant impact on TTP and OS in multivariate analysis. Moreover, there were no notable differences between the groups in terms of prior treatments and setting of study treatments, which rule out the role of these factors on the favourable results of EoP arm.

The myelotoxicity, however, was higher in the EoP arm when compared to T. In all, 21 patients in the EoP arm $v$ s only three patients in the paclitaxel arm had at least 7 days of treatment delays due to myelosuppression. Likewise, nausea and asthenia were more common in the EoP arm. Probably more myelotoxicity in each arm would be noted if CBCs were repeated weekly instead of every 3 weeks. Two deaths in each arm following febrile neutropenia also suggest that the grade 4 neutropenia was more common than noticed for both EoP and paclitaxel arms.

Toxicities observed in several phase II as well as in two randomised trials assessing the efficacy of EP in breast cancer have limited the use of this combination in breast cancer (Giaccone et al, 1988; Krook et al, 1990; Cocconi et al, 1991;
Remick et al, 1996; Icli et al, 2001). However, the dosage of cisplatin in all these trials was higher when compared to the present trial $\left(100\right.$ vs $\left.70 \mathrm{mg} \mathrm{m}^{-2}\right)$. A randomised phase 2 study comparing low $\left(60 \mathrm{mg} \mathrm{m}^{-2}\right)$ vs high $\left(100 \mathrm{mg} \mathrm{m}^{-2}\right)$ doses of cisplatin in the EP combination against breast cancer concluded that the dose of cisplatin had no significant effect in terms of TTP and OS (Ceci et al, 1995). Also, the dose intensity of both cisplatin and etoposide in the present trial was found to have no significant impact on both TTP and OAS in the multivariate analysis. Therefore, it may be premised that similar efficacy could be achieved by lower and less toxic dosages of both cisplatin and oral etoposide in $\mathrm{ABC}$.

In the $1990 \mathrm{~s}$, paclitaxel $175 \mathrm{mg} \mathrm{m}^{-2}$ i.v. every 3 weeks was considered as the treatment of choice following anthracyclines for patients with ABC (Nabholtz et al, 1996). Our randomised trial of EoP $v s$ paclitaxel proves that EoP is more active in this group of patients. Significantly improved survival in the EoP arm in this trial is a rarely observed phenomenon in randomised trials of $A B C$ treatment. Approximately 10 times lower price of EoP than paclitaxel also favours this treatment, especially in countries with limited sources of health expenditure. However, we should admit that absence of quality of life assessment is the weaknesses of the present trial.

In conclusion, results obtained in the present trial supports the use of EoP in the treatment of ABC. Further randomised trials will enlighten the efficacy of this relatively old treatment when compared to the new active drugs in breast cancer. Likewise, it will be interesting to see the efficacy of this treatment combined with herceptin in HER2-positive patients.

\section{ACKNOWLEDGEMENTS}

We thank the following members of the Turkish Oncology Group for their active participation: Adnan Aydiner (Istanbul), Gulistan Bulutlar (Istanbul), Dilek Dincol (Ankara), Abdurrahman Isikdogan (Diyarbakir), Halil Kavgaci (Trabzon), Feyyaz Ozdemir (Trabzon), Mustafa Samur (Antalya) and Yavuz Ozisik (Ankara). We also thank Nuran Caglayan for her help in data processing.

\section{REFERENCES}

Abrams JS, Vena DA, Baltz J, Adams J, Montello M, Christian M, Onetto N, Desmond-Hellmann S, Canetta R, Friedman MA (1995) Paclitaxel activity in heavily pretreated breast cancer: a National Cancer Institute referral center. J Clin Oncol 13: 2056-2065

Athanassiades P, Bacoyiannes H, Kontoyiannes D (1986) Etoposide and cisdichlorodiammine platinum in advanced breast carcinoma resistant to previous chemotherapy. Chemioterapia 5: 125-127

Atienza DM, Vogel CL, Trock B, Swain SM (1995) Phase II study of oral etoposide for patients with advanced breast cancer. Cancer 12: $2485-2490$

Bonneterre J, Roche H, Monnier A, Guastalla JP, Namer M, Fargeot P, Assadourian S (2002) Docetaxel vs 5-fluorouracil plus vinorelbine in metastatic breast cancer after anthracycline therapy failure. Br J Cancer 87: $1210-1215$

Bontenbal M, Planting AS, Verweij J, de Wit R, Kruit WH, Stoter G, Klijn JG (1995) Second-line chemotherapy with long-term low-dose oral etoposide in patients with advanced breast cancer. Breast Cancer Res Treat 34: $185-189$

Burchenal JH, Kalaher K, Dew K, Lokys L (1979) Rationale for development of platinum analogs. Cancer Treat Rep 63: 1493-1498

Calvert AH, Lind MJ, Millward MM, Cantwell BM, Gumbrell L, Proctor M, Simmons D, Chapman F, Robinson A, Charlton C (1993) Long-term oral etoposide in metastatic breast cancer: clinical and pharmacokinetic results. Cancer Treat Rev 19(Suppl C): $27-33$
Ceci G, Bisagni G, Cocconi G, Rodino C, Belsanti V, Bertusi M, Buzzi F, Bacchi M (1995) Cisplatin and VP-16 in metastatic breast carcinoma as third line chemotherapy: a randomised study comparing low vs high dose of cisplatin. Tumori 81: 241-244

Cocconi G, Bisagni G, Bacchi M, Boni C, Bartolucci R, Ceci G, Colozza MA, De Lisi V, Lottici R, Mosconi AM (1991) Cisplatin and etoposide as firstline chemotherapy for metastatic breast carcinoma: a prospective randomized trial of the Italian Oncology Group for Clinical Research. $J$ Clin Oncol 9: 664-669

Cocconi G, Tonato M, Dicostanzo F, Bisagni G, Belsanti V, Buzzi F, Ceci G (1986) Platinum and etoposide in chemotherapy refractory metastatic breast cancer. A phase II trial of the Italian Oncology Group for Clinical Research (GOIRC). Eur J Clin Oncol 22: 761 - 764

Cox EB, Burton GV, Olsen GA, Vugrin D (1989) Cisplatin and etoposide: an effective treatment for refractory breast carcinoma. Am J Clin Oncol 12: $53-56$

Fried G, Stein ME, Haim N (2000) Clinical activity of cisplatin and prolonged oral administration of etoposide in previously treated, anthracycline-resistant, metastatic breast cancer patients: a phase II study. Med Ped Oncol 34: 10-13

Giaccone G, Donadio M, Ferrati P, Calciati A (1988) Cisplatin and etoposide in chemotherapy-refractory advanced breast cancer. Tumori 74: $191-193$

Icli F, Akbulut H, Dinçol D, Onur H, Demirkazik A, Cam R, Cay F, Demirci S, Uner A, Erekul S (2001) A randomized trial of four cycles of adjuvant 
AC (adriamycin+cyclophosphamide) \pm two cycles of EP (etoposide+ cisplatin) in node positive patients with breast cancer. Ann Oncol 12: $1011-1013$

Icli F, Demirkazik A (1998) Cisplatin and oral etoposide (PEO) in heavily pretreated patients with advanced breast cancer. Proc ASCO 17: 560 (abstr)

Icli F, Günel N, Dinçol D, Gunel N, Karaoguz H, Demirkazik A (1992) Cisplatin plus VP-16 combination chemotherapy in advanced refractory breast cancer. J Surg Oncol 50: 251-253

Krook JE, Loprinzi CL, Schaid DJ, Kardinal CG, Mailliard JA, Pfeifle DM, Ellison NM, Reuter NF, Nelimark RA (1990) Evaluation of the continuous infusion of etoposide plus cisplatin in metastatic breast cancer. A colloborative North Central Cancer Treatment Group Mayo Clinic phase II study. Cancer 65: 418-421

Mabel JA, Little AD (1981) Therapeutic synergism in murine tumors for combination of cisdiammine-dichloroplatinum with VP16-213 or BCNU. Proc AACR-ASCO 22: 357

Martin M, Lluch A, Casado A, Santabarbara P, Adrover E, Valverde JJ, Lopez-Martin JA, Rodriguez-Lescure A, Azagra P, Garcia-Conde J (1994) Clinical activity of chronic oral etoposide in previously treatment metastatic breast cancer. J Clin Oncol 12: 986-991

Nabholtz JM, Gelmon K, Bontenbal M, Spielmann M, Catimel G, Conte P, Klaassen U, Namer M, Bonneterre J, Fumoleau P, Winograd B (1996) Multicenter, randomized comparative study of two doses of paclitaxel in patients with metastatic breast cancer. J Clin Oncol 14: $1858-1867$

Nabholtz JM, Senn HJ, Bezwoda WR, Melnychuk D, Deschenes L, Douma J, Vandenberg TA, Rapoport B, Rosso R, Trillet-Lenoir V, Drbal J, Molino A, Nortier JW, Richel DJ, Nagykalnai T, Siedlecki P, Wilking N, Genot JY, Hupperets PS, Pannuti F, Skarlos D, Tomiak EM, Murawsky M, Alakl M, Aapro M (1999) Prospective randomized trial of docetaxel $v s$ mitomycin plus vinblastine in patients with metastatic breast cancer progressing despite previous anthracycline-containing chemotherapy. 304 Study Group. J Clin Oncol 17: 1413-1424
Palombo H, Estape J, Vinolas N, Grau JJ, Mane JM, Daniels M, Mellado B (1994) Chronic oral etoposide in advanced breast cancer. Cancer Chemother Pharmacol 33: 527-529

Ravdin P, Erban J, Overmoyer B, Budd GT, Hutchins L, Lower E, Laufman L, Sundaram S, Urba W, Olsen S, Meyers ML, Jones S (2003) Phase III comparison of docetaxel and paclitaxel in patients with metastatic breast cancer. Eur J Cancer 1(Suppl 5): S201

Remick SC, Chmura M, Drior CT, Sporn J, Healey B, Hilstro J, DeConti RC, Horton J, Ruckdeschel JC, Harper GR (1996) Concurrent 72 h continuous infusion of etoposide and cisplatin in metastatic breast cancer. Am J Clin Oncol 19: $125-131$

Sjöström J, Blomqvist C, Mouridsen H, Pluzanska A, Ottosson-Lonn S, Bengtsson NO, Ostenstad B, Mjaaland I, Palm-Sjovall M, Wist E, Valvere V, Anderson H, Bergh J (1999) Docetaxel compared with sequential methotrexate and 5-fluorouracil in patients with advanced breast cancer after anthracycline failure: a randomised phase III study with crossover on progression by the Scandinavian Breast Group. Eur J Cancer 35: $1194-1201$

Sledge Jr GW (1991) Etoposide in the management of metastatic breast cancer. Cancer 67: 266-270

Sledge Jr GW, Roth BJ (1989) Cisplatin in the management of breast cancer. Semin Oncol 16: $110-115$

Talbot DC, Moiseyenko V, Van Belle S, O'Reilly SM, Alba Conejo E, Ackland S, Eisenberg P, Melnychuk D, Pienkowski T, Burger HU, Laws S, Osterwalder B (2002) Randomised, phase II trial comparing oral capecitabine (Xeloda) with paclitaxel in patients with metastatic/ advanced breast cancer pretreated with anthracyclines. $\mathrm{Br} J$ Cancer 86 $1367-1372$

Winer EP, Berry DA, Woolf S, Duggan D, Kornblith A, Harris LN, Michaelson RA, Kirshner JA, Fleming GF, Perry MC, Graham ML, Sharp SA, Keresztes R, Henderson IC, Hudis C, Muss H, Norton L (2004) Failure of higher-dose paclitaxel to improve outcome in patients with metastatic breast cancer: cancer and leukemia group B trial 9342. J Clin Oncol 22: $2061-2068$ 